Volume 4, Number 2, 2018

\title{
Design of Optimal Filter for Analog Signal
}

\author{
Roman Fedoryshyn $^{a^{*}}$, Sviatoslav Klos ${ }^{a}$, Volodymyr Savytskyi $^{a}$, Yevhen Pistun ${ }^{a}$, Miroslaw Woloszyn $^{b}$ \\ ${ }^{a}$ Lviv Polytechnic National University, 12 S. Bandera St., Lviv, 79013, Ukraine \\ ${ }^{b}$ Gdansk University of Technology, 11/12 G. Narutowicza St., Gdansk, 80-233, Poland
}

Received: November 09, 2018. Revised: November 29, 2018. Accepted: December 07, 2018.

(C) 2018 The Authors. Published by Lviv Polytechnic National University.

\begin{abstract}
The technique for designing the optimal value of the filter time constant for analog signal is presented in the paper. This technique is based on the objective function which takes into account the quality index of the filtration process and the dynamic error of the filtered signal. The experimental study of the transient processes in a thermal plant was carried out in order to analyze the influence of the filter parameters on the quality of the filtration process. The optimal value of the filter time constant was designed on the basis of the developed technique for the obtained experimental data. The experimental transient process was compared to the filtered one which was obtained with application of a filter with an optimal time constant. Application of the developed technique for designing the optimal time constant in the automated measurement and control systems will ensure high quality of the filtration process and small dynamic error of the filtered signal.
\end{abstract}

Keywords: filter; time constant; optimization; analog signal; dynamic error; objective function.

\section{Introduction}

The analog signal filtration is often used in the up-to-date automated measurement and control systems. The main purpose of the filtration process is to eliminate the disturbances (noise) and to allow the useful signal to pass. Application of a filter in an automatic control system based on a step controller or a continuous controller provides elimination of the undesired operation of the controller and improvement of the automatic control quality.

When designing a filter there is often a problem of choosing the filter structure and defining the numerical values of its tuning parameters. Nowadays the following two types of filters are most widely applied in the industrial automation systems based on microprocessor controllers: exponential filter and moving average filter. The structures of these filters are known and their tuning parameters can be set in a definite range depending on the process for which the technological parameter is measured.

Setting a too small value of the time constant for the exponential filter will lead to a low quality of the filtration process because not all the disturbances (noises) will be filtered (removed). Setting a too big value of the filter time constant will provide a good quality of filtration, however it will lead to a significant delay of the filtered signal which, in turn, will cause a big value of the dynamic error in the filtered signal. That is why there is a problem of defining such a value of the filter time constant at which a good quality of the filtration process would be ensured together with a small dynamic error of the filtered signal. To solve this problem the technique for designing the optimal value of the filter time constant was developed. This technique is based on the objective function which takes into account the quality index of the filtration process and the dynamic error of the filtered signal.

Optimization of filters is discussed in [1]-[3], however these works are mostly focused on optimization of the filter structure and less attention is paid to defining the optimal numerical values of the filter tuning parameters.

\footnotetext{
"Corresponding author. Email address: romanfedoryshyn@yahoo.com
}

This paper should be cited as: R. Fedoryshyn, S. Klos, V. Savytskyi, Y. Pistun, M. Woloszyn. Design of optimal filter for analog signal. Energy Eng. Control Syst., 2018, Vol. 4, No. 2, pp. 93 - 102. https://doi.org/10.23939/jeecs2018.02.093 
The goal of this work is to present the developed technique for designing the optimal value of the exponential filter time constant taking into account the dynamic properties of the controlled plant. The technique was developed on the basis of the results of experimental study of the transient processes in a thermal plant.

\section{Filters of analog signals}

In the analog signal processing, the filter is a device for passing the desired frequencies of the electric signal and for suppressing the undesired frequencies. In the digital signal processing, the digital filter is a hardware or software tool for any kind of digital signal processing with the properties of a linear time-invariant system [4]-[6]. Depending on the shape of the amplitude frequency response curve there are four types of filters:

- low-pass filters (they pass all the frequencies below the cutoff frequency $f_{c}$ );

- high-pass filters (they pass all the frequencies higher than the cutoff frequency $f_{c}$ );

- band-pass filters (they pass all the frequencies within the range from $f_{c 1}$ to $f_{c 2}$ );

- band-stop filters (they pass all the frequencies outside the range from $f_{c 1}$ to $f_{c 2}$ ).

Since it is impossible to implement the ideal amplitude frequency response (AFR) in a device, various approximation methods are applied during the filter design. There are the following types of filters depending on the AFR approximation function:

- Butterworth filter (its main advantage is the absence of the ripple in the pass band and in the stop band, however this filter has a slow roll-off and it is difficult and expensive to implement a highly selective filter since a high order of the filter is needed);

- Chebyshev type 1 and type 2 filters (they have a steeper roll-off, however there is ripple in the pass band (type 1) or in the stop band (type 2));

- elliptical (Cauer) filter (it has the steepest roll-off, however there is ripple both in the pass band and in the stop band).

There are also Bessel, Lagrange, Gaussian and other filters known in addition to those listed above.

The main advantages of the digital filters as compared to the analog ones are as follows:

- high accuracy (in the analog filters the accuracy is limited by the tolerance for the elements);

- stability in time (there is no drift of parameters depending on the environmental conditions);

- flexibility in tuning and simple change of the setting parameters;

- small dimensions.

There are also some drawbacks of the digital filters in comparison with the analog ones:

- limited range of operation due to the Nyquist frequency;

- difficulties with operation in the real-time mode, since all the computations need to be done within the sampling period;

- high resolution of ADC and DAC is needed to provide high accuracy of the filter.

The process of digital filtration consists in summarizing a definite number of the input and previous output samples:

$$
\begin{aligned}
& y_{n}=b_{0} x_{n}+b_{1} x_{n-1}+\ldots+b_{k} x_{n-k}- \\
& -a_{1} y_{n-1}-a_{2} y_{n-2}-\ldots-a_{m} y_{n-m},
\end{aligned}
$$

where $y_{n}$ is the current output sample; $x_{n}$ is the current input sample; $y_{n-i}$ are the previous output samples; $x_{n-i}$ are the previous input samples; $b_{i}$ are the coefficients of the input samples; $a_{i}$ are the coefficients of the output samples.

Depending on which samples take part in the computation of the output value, the following two categories of filters are considered:

- finite impulse response (FIR) filters (only input samples are used for computation of the output value);

- infinite impulse response (IIR) filters (both input and previous output samples are used for computation of the output value). 
The industrial low-pass filters are usually based on the following two types of filters: the moving average filter (FIR filter) and the exponential filter (IIR filter) [7].

The moving average filter with five samples used for computing the output sample can be described by the equation:

$$
y_{n}=\frac{1}{5}\left(x_{n-2}+x_{n-1}+x_{n}+x_{n+1}+x_{n+2}\right) .
$$

In this equation, both samples before and after a given moment of time $n$ take part in computation of the current output sample. That is why there is no delay in the filtered signal. This type of the filtration algorithm is called non-causal. And it cannot be used for the real-time applications.

The output sample of a real-time filter is computed on the basis of the previous samples. There is a delay of the output samples with respect to the input ones. This filter is called causal and it can be described by the equation:

$$
y_{n}=\frac{1}{5}\left(x_{n}+x_{n-1}+x_{n-2}+x_{n-3}+x_{n-4}\right) .
$$

The moving average filter is simple, however at equal coefficients it becomes inert and there is a slow response of the filter to the variation of the input signal.

The exponential filter which is also called the autoregressive-moving-average (ARMA) filter can be described by the equation:

$$
y_{n}=\frac{h}{T+h} x_{n}+\frac{T}{T+h} y_{n-1},
$$

where $h$ is the analog signal sampling period; $T$ is the filter time constant.

The current filtered sample $y_{n}$ is defined by summing the previous filtered sample $y_{n-1}$ and the current input sample $x_{n}$ with the corresponding weighting coefficients.

\section{Experimental study}

To evaluate the influence of the filter parameters on the quality of the filtration process the results of the experimental study were obtained. The transient processes in a thermal plant (electric oven) were studied. Air temperature at the output of the oven was the output variable of the plant. Fifteen step response curves in total were registered. The sampling period during the analog signal logging was $1 \mathrm{~s}$. The experimental facility and the data logging processes are described in details in [8]. The normalized step response curves obtained during the experimental study are presented in Fig. 1 . The curves $1_{19}-10_{19}$ were obtained during the first day of the experimental study and the curves $1_{20}-5_{20}$ during the second day of the study.

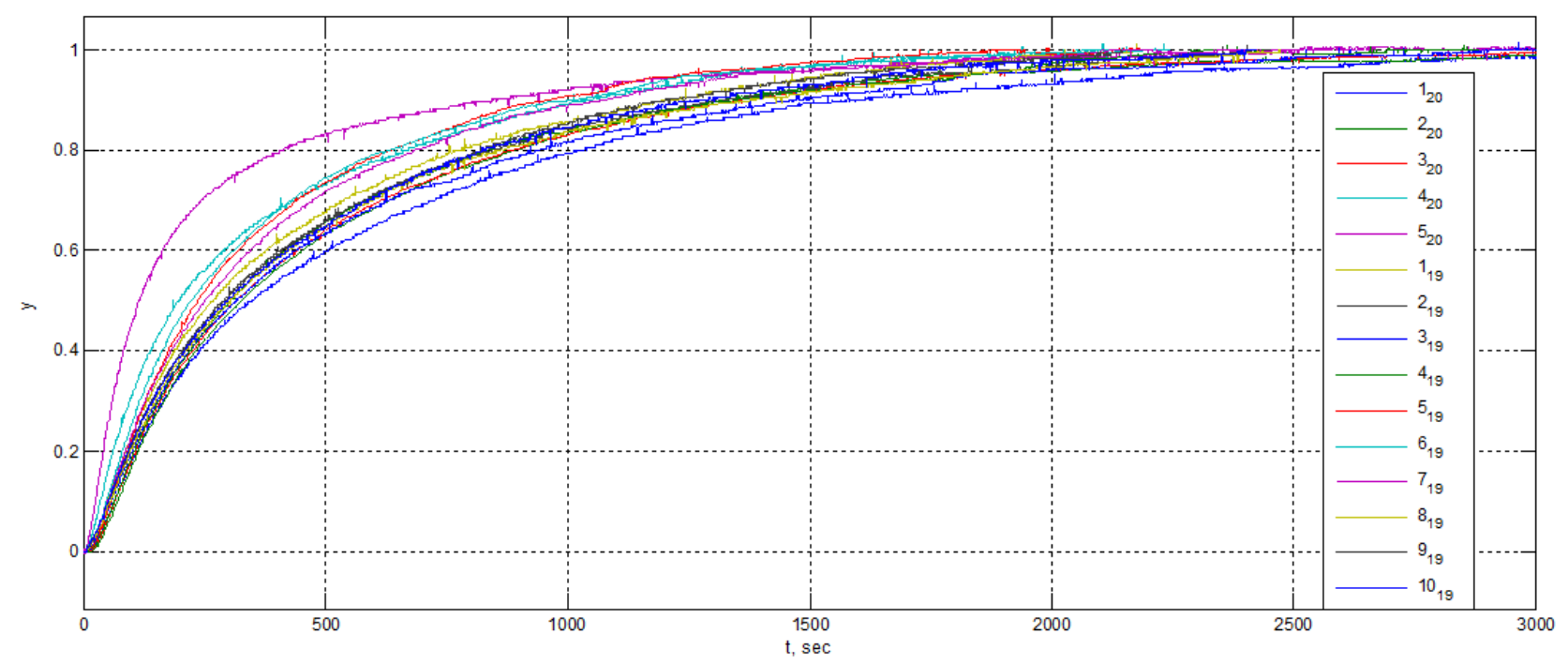

Fig.1. Normalized step response curves obtained during the experimental study. 
It can be seen from Fig. 1 that the registered step response curves contain both useful signal and the disturbances (noise) which occurred during the experiment. These disturbances look like abrupt, brief deviations of the registered points from the main current value of the signal. In order to eliminate these disturbances during operation of the measurement system in real-time mode it is proposed to apply the exponential filter with the time constant designed according to the technique presented below.

We can also see from Fig. 1 that the registered curves have different dynamics. For designing the optimal value of the filter time constant the curve $5_{20}$ is chosen (upper violet curve in Fig.1). This curve has the highest rate of signal change. Such a choice of the curve is explained by the fact that the impact of the filter time constant on the dynamic error of measurement is the most significant for the signal with the highest rate of change. And for the signals with a smaller rate of change this influence will be less considerable.

\section{Design of optimal filter}

In order to design the optimal value of the time constant for the exponential filter according to the developed technique the following eight steps should be accomplished.

Step 1. Computation of the smoothed analog signal by means of the non-causal moving average filter using the following formula:

$$
y_{n}^{s}=\frac{1}{5}\left(y_{n-2}^{e}+y_{n-1}^{e}+y_{n}^{e}+y_{n+1}^{e}+y_{n+2}^{e}\right),
$$

where $y^{s}$ are smoothed samples; $y^{e}$ are experimental samples.

The example of the smoothed step response curve for the experimental curve $5_{20}$ is presented in Fig.2. The step response curve is presented in the time range from 0 to $20 \mathrm{~s}$ for a better visual demonstration.

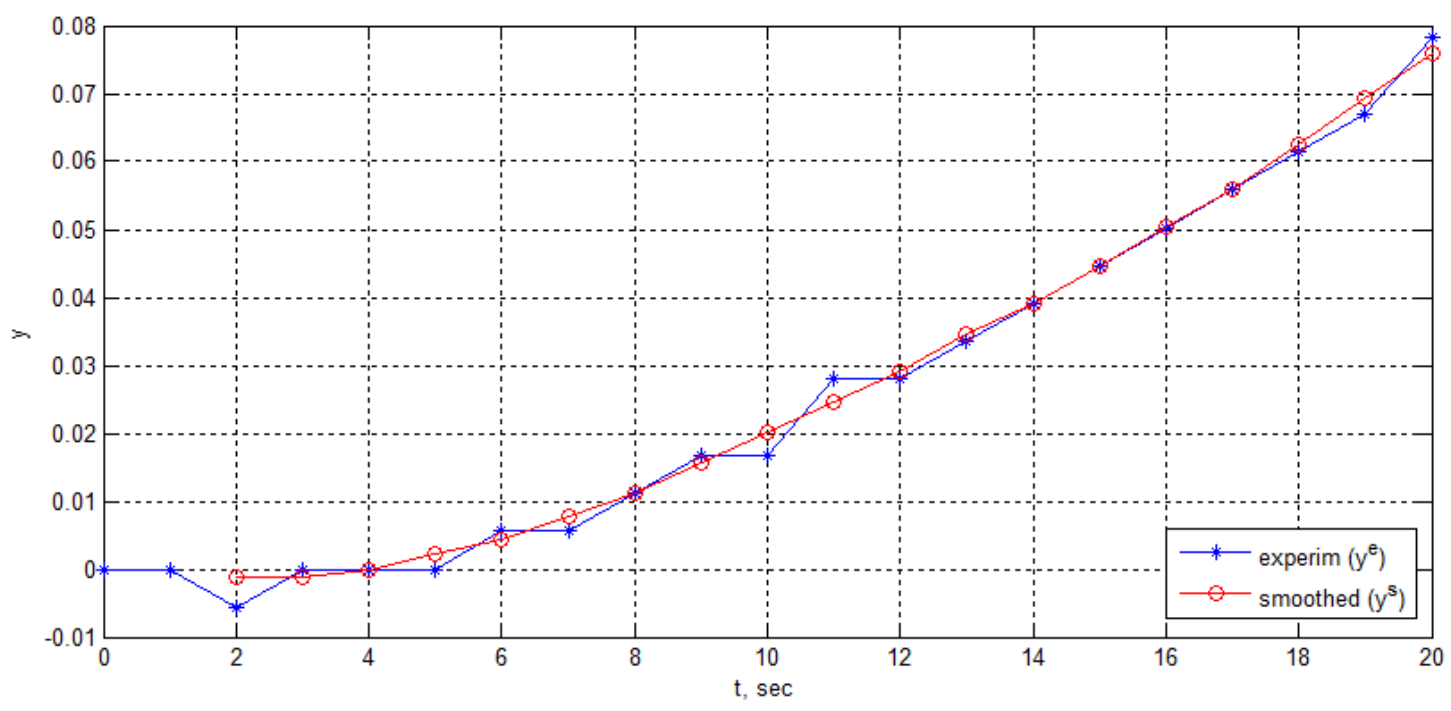

Fig.2. Comparison of the smoothed $\left(y^{s}\right)$ and experimental $\left(y^{e}\right)$ step response curves.

Step 2. Computation of the mean square of the experimental samples deviation from the smoothed experimental samples according to the formula

$$
D=\frac{1}{N-4} \sum_{i=3}^{N-2}\left(y_{i}^{e}-y_{i-2}^{s}\right)^{2}
$$

where $N$ is the number of registered experimental samples of the analog signal; $y^{e}$ are experimental samples; $y^{s}$ are smoothed experimental samples obtained in step 1. 
In formula (6), the sum of squares starts from the third sample $(i=3)$ and ends by the third sample from the end $(N-2)$ which is caused by the fact that there are no first two and last two samples in the smoothed signal $\left(y^{s}\right)$. This is the peculiarity of the non-causal moving average filter. There is $(N-4)$ in the denominator which is also caused by the absence of the first two and the last two samples in the smoothed signal.

Step 3. Filtration of the experimental analog signal by means of the exponential filter with the time constant $T_{f}=1 \mathrm{~s}$. The example of the model for filtration of the experimental signal in Simulink is presented in Fig.3. The experimental samples of the registered signal $\left(y^{e}\right)$ are entered in the block Signal 1. The exponential filter is presented by the block filter (the first-order lag element with the time constant $\mathrm{T}_{-} \mathrm{f}$ ). The signal $y^{f 1}$ will be obtained as the result of the filtration. The comparison of the experimental and the filtered analog signal is presented in Fig.4.

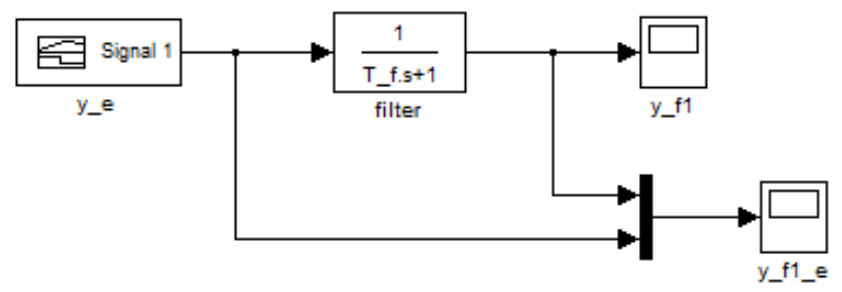

Fig.3. Example of the model for filtration of the experimental signal by means of the exponential filter in Simulink.

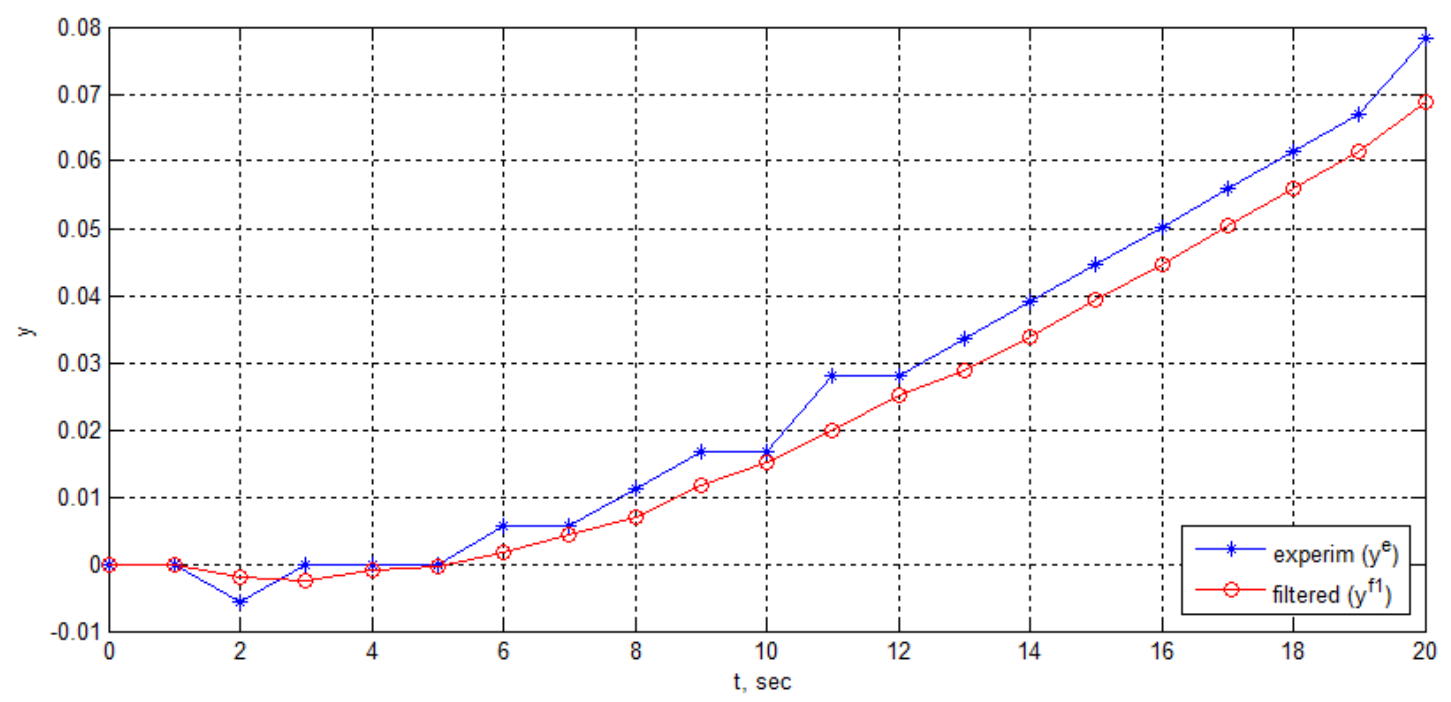

Fig.4. Comparison of the experimental analog signal $\left(y^{e}\right)$ and the filtered signal $\left(y^{f 1}\right)$ by means of the exponential filter with the time constant $T_{f}=1 \mathrm{~s}$.

Step 4. Computation of the smoothed filtered signal by means of the non-causal moving average filter using the following formula:

$$
y_{n}^{s 1}=\frac{1}{5}\left(y_{n-2}^{f 1}+y_{n-1}^{f 1}+y_{n}^{f 1}+y_{n+1}^{f 1}+y_{n+2}^{f 1}\right)
$$

The comparison of the filtered $\left(y^{f 1}\right)$ and the smoothed filtered signal $\left(y^{s 1}\right)$ is presented in Fig.5.

Step 5. Computation of the mean square of the filtered samples $\left(y^{f 1}\right)$ deviation from the smoothed filtered samples $\left(y^{s 1}\right)$ according to the formula

$$
D=\frac{1}{N-4} \sum_{i=3}^{N-2}\left(y_{i}^{f 1}-y_{i-2}^{s 1}\right)^{2} .
$$




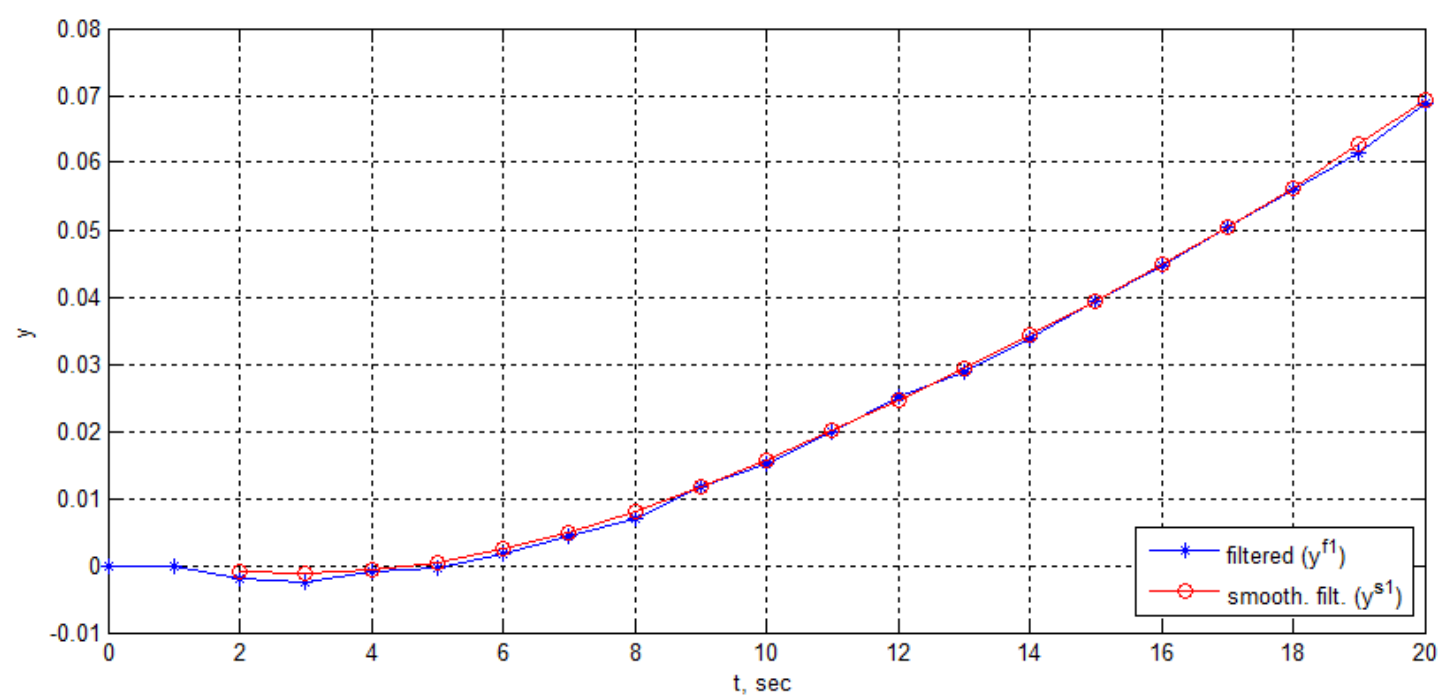

Fig.5. Comparison of the filtered $\left(y^{f 1}\right)$ and the smoothed filtered analog signal $\left(y^{s 1}\right)$.

Step 6. Computation of the maximum dynamic error of the smoothed filtered samples $\left(y^{s 1}\right.$, obtained in step 4) with respect to the smoothed experimental samples $\left(y^{s}\right.$, obtained in step 1). Since the normalized experimental step response curve varies from 0 to 1 (see Fig.1), the maximum relative reduced error can be calculated according to the formula

$$
\delta_{\max }=\max \left(\left|y^{s 1}-y^{s}\right| \times 100\right) .
$$

The comparison of the smoothed experimental signal $\left(y^{s}\right)$ and the smoothed filtered signal $\left(y^{s 1}\right)$ is presented in Fig.6.

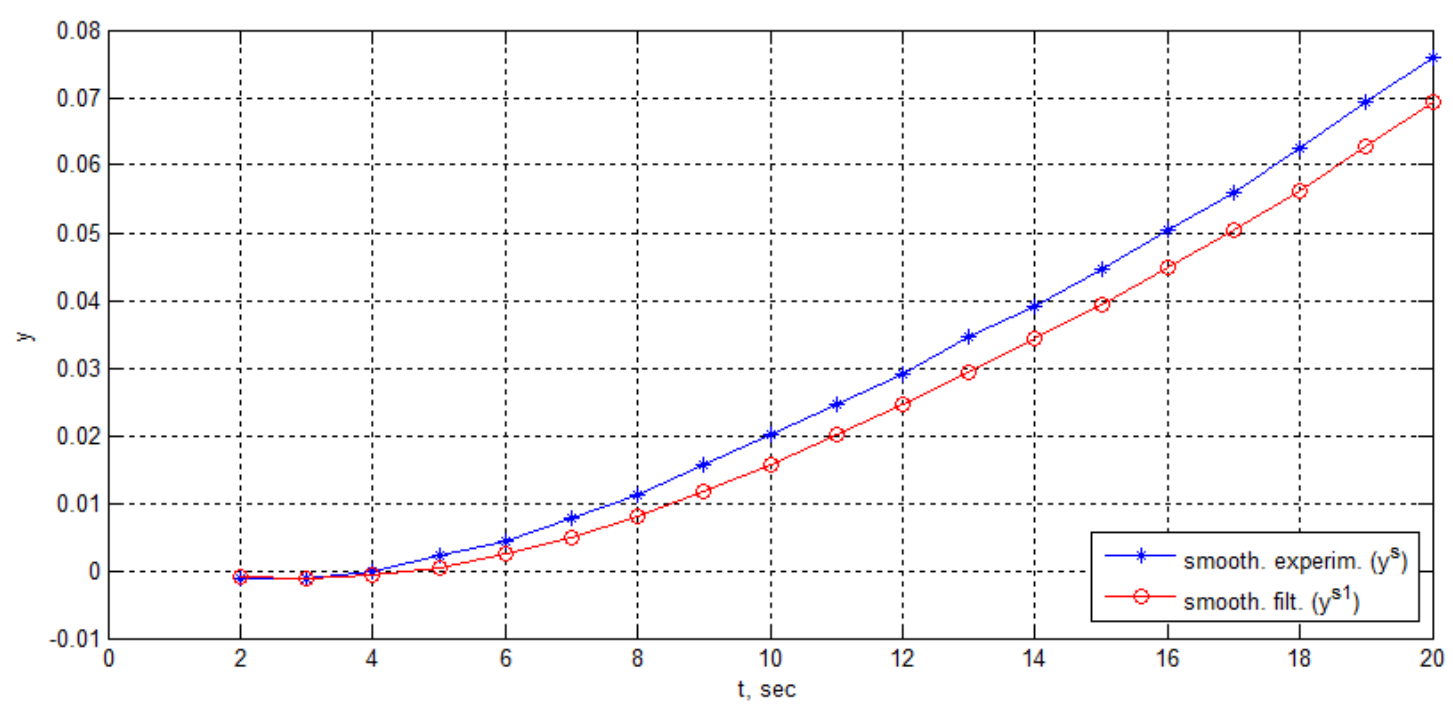

Fig.6. Comparison of the smoothed experimental signal $\left(y^{s}\right)$ and the smoothed filtered signal $\left(y^{s 1}\right)$.

Step 7. Accomplishment of steps 3-6 for the exponential filter time constant $T_{f}=2,3,4, \ldots n \mathrm{~s}$. The computation should be done until the maximum dynamic error $\delta_{\max }$ does not exceed $10 \%$. At the result of the computation, the dependence of the deviation mean square $D$ on the filter time constant $T_{f}$ will be obtained as well as the dependence of the maximum dynamic error $\delta_{\max }$ on the filter time constant $T_{f}$ will be obtained. These dependences are presented in Table 1 and in Fig.7, Fig. 8 for the experimental step response curve $5_{20}$. 
It can be seen from Table 1 that the last value of the filter time constant for which the maximum dynamic error does not exceed $10 \%$ is equal to $18 \mathrm{~s}$.

Table 1. Dependence of the deviation mean square $D$ and the maximum dynamic error $\delta_{\max }$ on the filter time constant $T_{f}$.

\begin{tabular}{|c|c|c||c|c|c||c|c|c||c|c|c|}
\hline$T_{f}, \mathrm{~s}$ & $D \times 10^{-6}$ & $\delta_{\max }, \%$ & $T_{f}, \mathrm{~s}$ & $D \times 10^{-6}$ & $\delta_{\max } \%$ & $T_{f}, \mathrm{~s}$ & $D \times 10^{-6}$ & $\delta_{\max } \%$ & $T_{f}, \mathrm{~s}$ & $D \times 10^{-6}$ & $\delta_{\max } \%$ \\
\hline \hline 0 & 4.528 & 0.00 & 5 & 0.046 & 3.18 & 10 & 0.012 & 5.95 & 15 & 0.006 & 8.29 \\
\hline 1 & 0.720 & 0.67 & 6 & 0.033 & 3.76 & 11 & 0.010 & 6.45 & 16 & 0.005 & 8.71 \\
\hline 2 & 0.240 & 1.33 & 7 & 0.024 & 4.34 & 12 & 0.009 & 6.94 & 17 & 0.005 & 9.14 \\
\hline 3 & 0.118 & 1.96 & 8 & 0.019 & 4.90 & 13 & 0.008 & 7.41 & 18 & 0.004 & 9.57 \\
\hline 4 & 0.070 & 2.59 & 9 & 0.015 & 5.44 & 14 & 0.007 & 7.86 & 19 & 0.004 & 10.01 \\
\hline
\end{tabular}

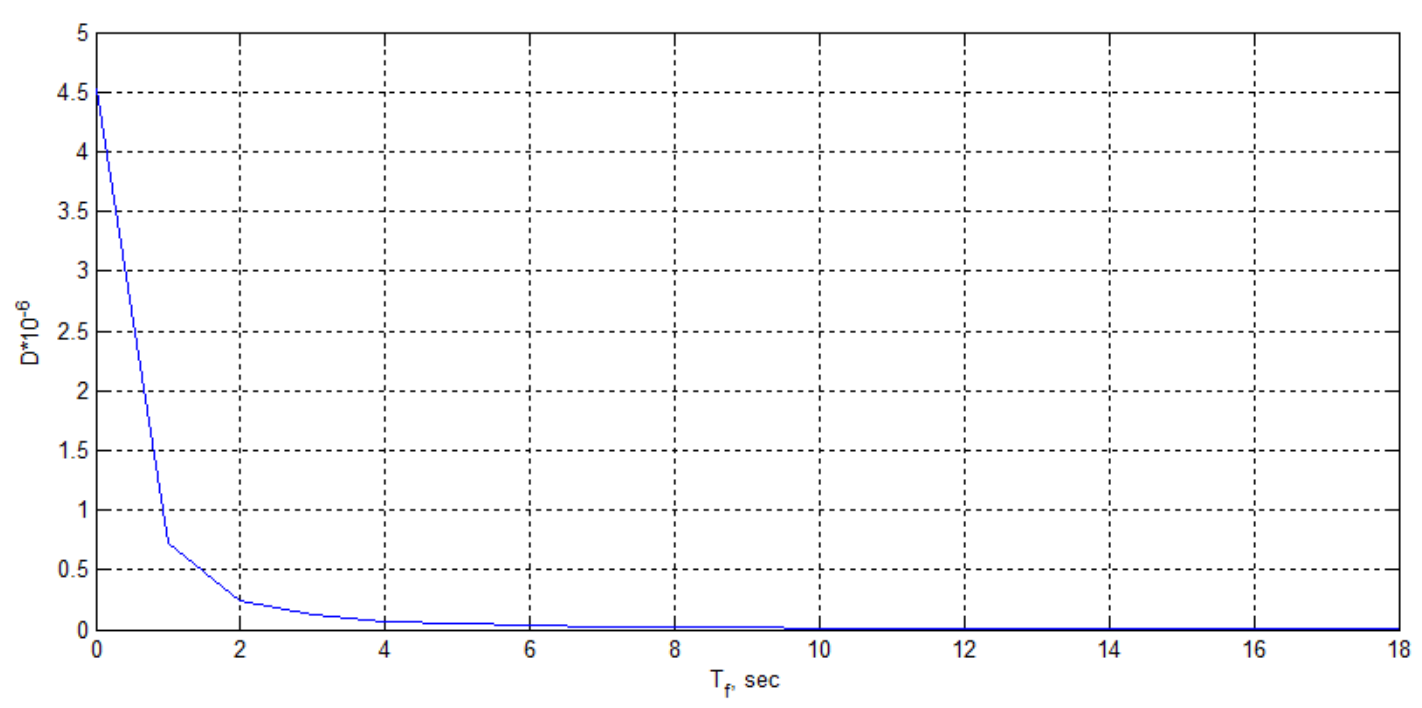

Fig.7. Dependence of the deviation mean square $D$ on the filter time constant $T_{f}$.

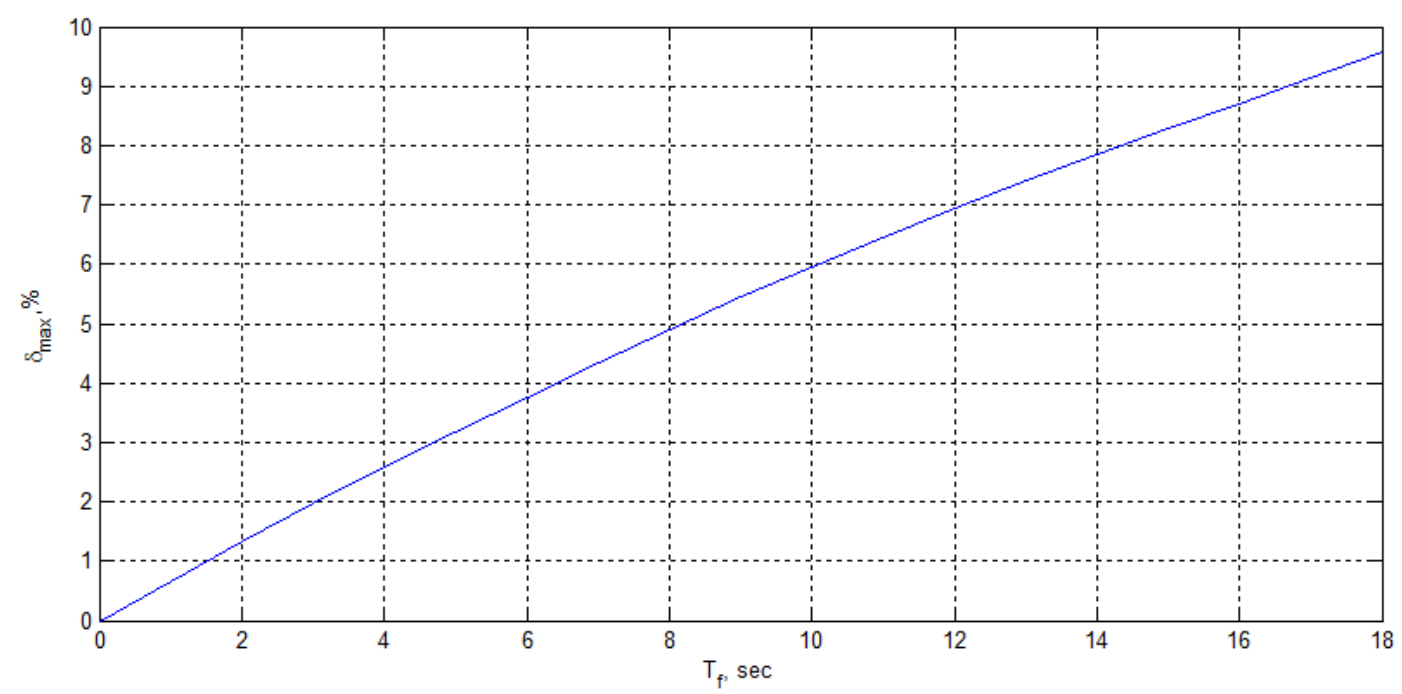

Fig.8. Dependence of the maximum dynamic error $\delta_{\max }$ on the filter time constant $T_{f}$.

The value $D$ represents the scattering of the filtered signal with respect to the smoothed filtered signal. This value can serve as the index of the filtration quality. The smaller the scattering of the filtered signal, the higher the quality of the filtration process is. As we can see from Fig.7, the increase of the filter time constant $T_{f}$ leads to the decrease of the deviation mean square $D$, i.e. to the improvement of the quality of the analog signal filtration. However, our attention should also be paid to the influence of the filter time constant $T_{f}$ on the dynamic error of the filtered signal $\delta_{\max }$. The increase of the filter time constant $T_{f}$ leads to the increase of this error (see Fig.8). 
To define the optimal value of the filter time constant it is proposed to apply a combined objective function. Computation of this objective function is presented in the next step.

Step 8. Computation of the objective function on the basis of the obtained arrays of the deviation mean square $D$ and the maximum dynamic error $\delta_{\max }$ according to the formula

$$
I\left(T_{f}\right)=D^{\prime}\left(T_{f}\right)+\delta_{\max }^{\prime}\left(T_{f}\right)
$$

where $D^{\prime}\left(T_{f}\right)$ is the reduced mean square of the deviation; $\delta_{\max }^{\prime}\left(T_{f}\right)$ is the reduced maximum dynamic error.

The reduced mean square values of the deviation are calculated as follows:

$$
D^{\prime}\left(T_{f}\right)=\frac{D\left(T_{f}\right)}{D(0)},
$$

where $D(0)$ is the first value of the deviation mean square (for the filter time constant $T_{f}=0 \mathrm{~s}$ ).

The reduced maximum dynamic errors are calculated as follows:

$$
\delta_{\max }^{\prime}\left(T_{f}\right)=\frac{\delta_{\max }\left(T_{f}\right)}{\delta_{\max }(n)},
$$

where $\delta_{\max }(n)$ is the last value of the maximum dynamic error (for the last value of the filter time constant $T_{f}=n \mathrm{~s}$ ).

The optimal time constant of the exponential filter shall be defined on the basis of the calculated values of the objective function. The optimal time constant is such a value of the time constant for which the objective function is minimal:

$$
T_{f}^{o p t}=\left.T_{f}\right|_{I=\min (I)}
$$

The curve of the objective function $I$ versus the filter time constant $T_{f}$ for the experimental step response curve $5_{20}$ is presented in Fig. 9 .

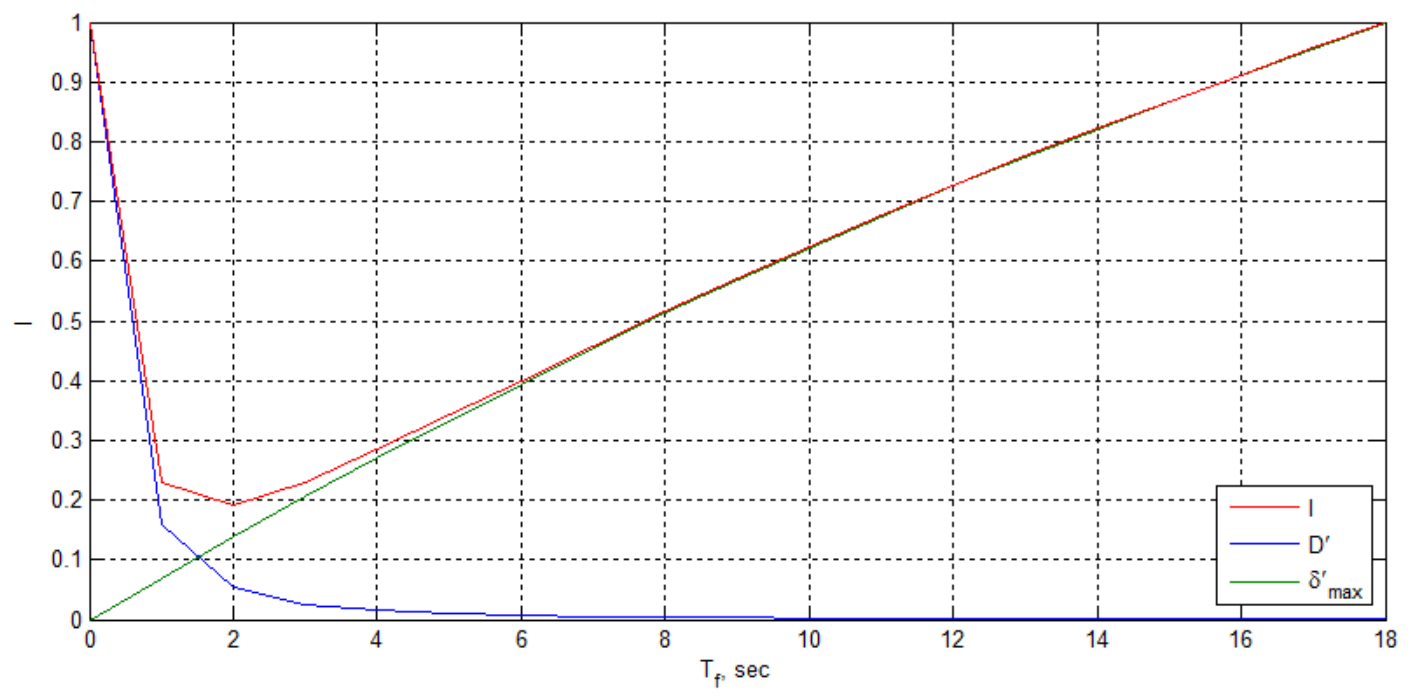

Fig.9. Curve of the objective function $I$ versus the filter time constant $T_{f}$.

As we can see from Fig.9, the optimal filter time constant for which the objective function takes a minimum value is equal $2 \mathrm{~s}$. At such a value of the filter time constant the maximum dynamic error of the filtered signal is equal $1.33 \%$ (see Table 1). The influence of the disturbances (noise) on the useful signal after filtration becomes almost 20 times less than it was in the unfiltered experimental signal (4.528/0.240, see Table 1). The comparison of the 
experimental step response curve and the filtered curve by means of the filter with the optimal time constant $T_{f}^{o p t}=2 \mathrm{~s}$ is presented in Fig. 10.

The filtered signal almost coincides with the experimental one (see, Fig.10,a) which means that the dynamic error of the filtered signal is insignificant. We can also see that the filtered signal varies smoothly without abrupt deviations (see, Fig.10,b) which means that the quality of the filtration process is high.

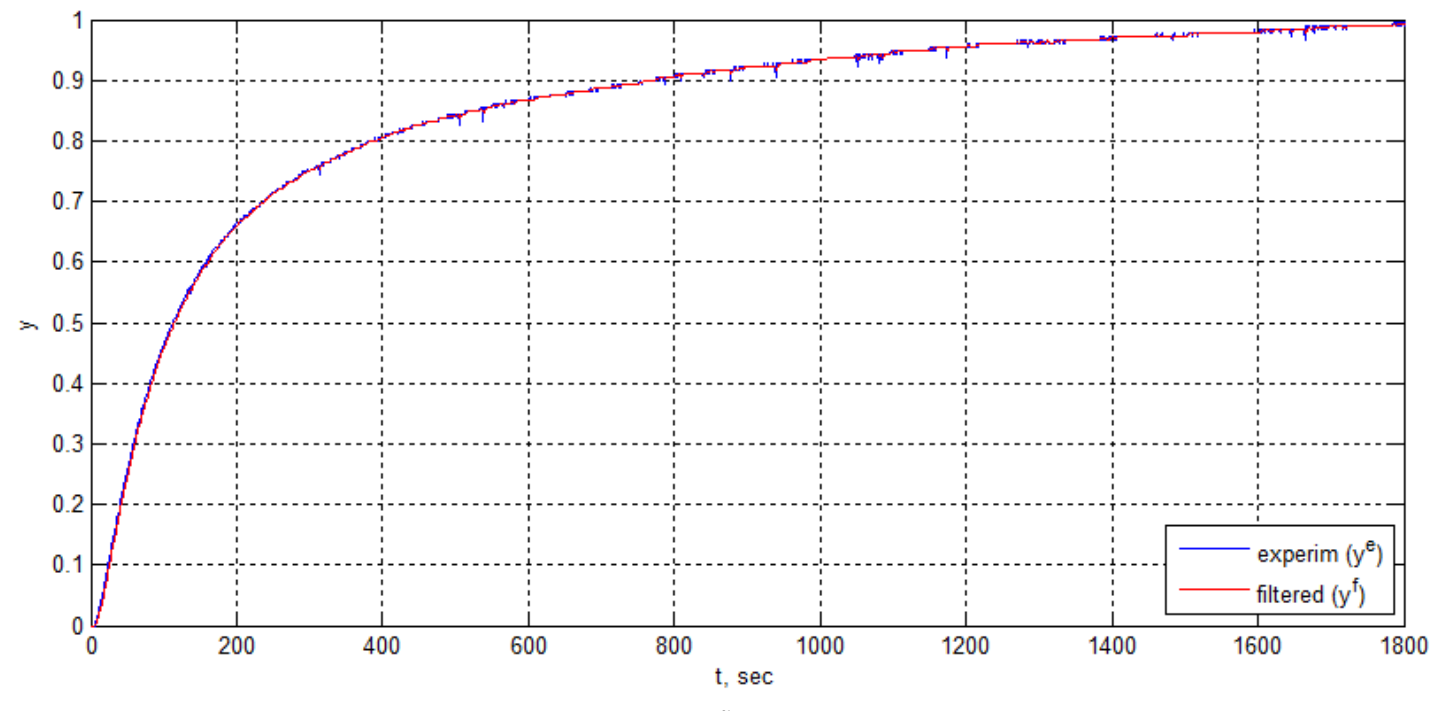

$a$

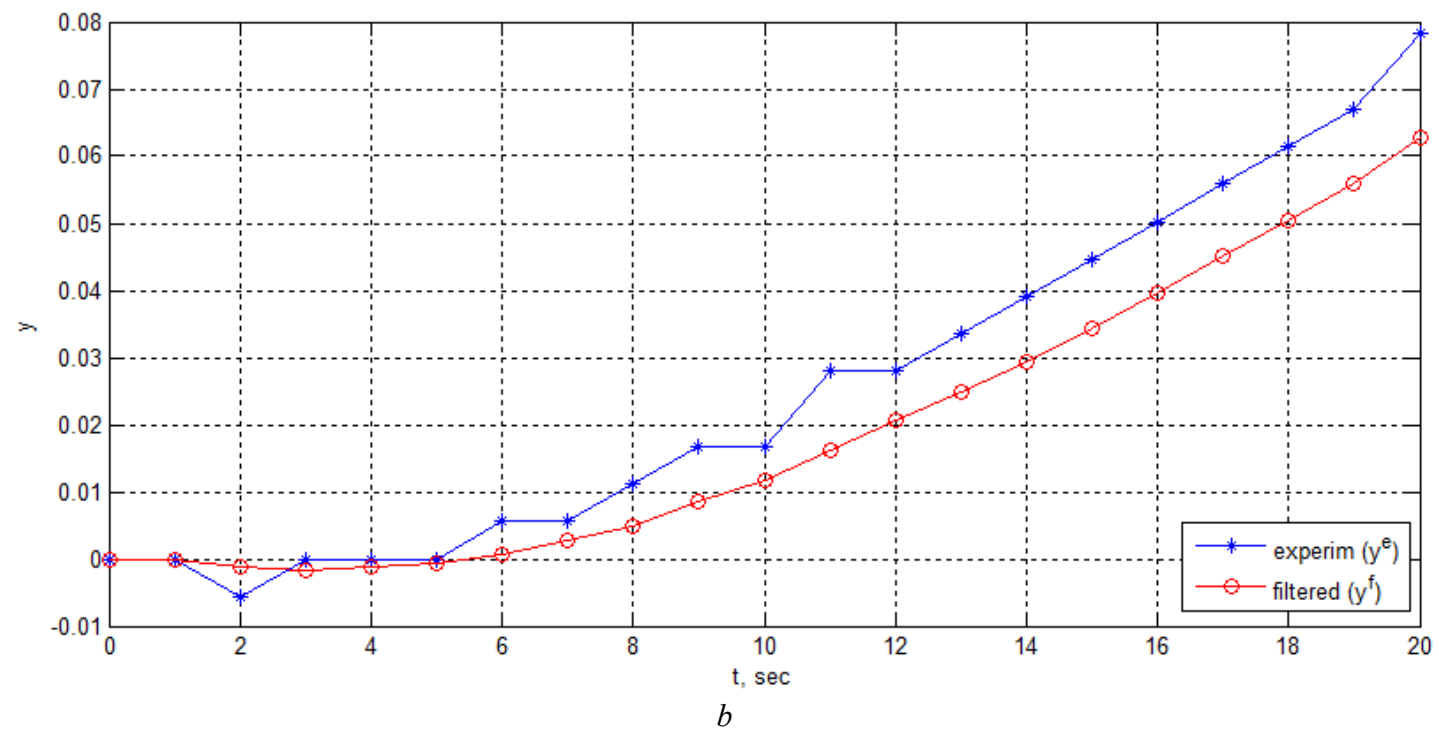

Fig.10. Comparison of the experimental step response curve and the filtered curve by means of the filter with the optimal time constant $T_{f}^{\text {opt }}=2 \mathrm{~s} \mathrm{(} a$ - whole curve; $b$ - part of the curve in the time range from 0 to $20 \mathrm{~s}$ ).

If there is a task of further decreasing the influence of the disturbances (noise) on the useful signal, for instance to make it 100 times smaller, then in this case the filter time constant should be increased up to $5 \mathrm{~s}(4.528 / 0.046$, see Table 1). However the maximum dynamic error here would rise up to $3.18 \%$. One more problem to be solved might be defining such a value of the filter time constant at which the maximum dynamic error of the filtered signal does not exceed $3 \%$. In this case the filter time constant should be set equal to $4 \mathrm{~s}$.

\section{Conclusion}

The technique for designing the optimal time constant of the exponential filter has been developed. This technique is based on the objective function which takes into account the quality index of the filtration process and the dynamic error of the filtered signal. The mean square of deviation of the filtered signal from the smoothed filtered 
signal is taken as the quality index of the filtration process. The filtered signal was smoothed by applying the noncausal moving average filter.

Based on the experimental step response curve for a thermal plant, the optimal value of the filter time constant was designed. This optimal value is equal to $2 \mathrm{~s}$. By setting such a time constant, the influence of the disturbances (noise) on the useful signal is reduced by 20 times after the filtration. The maximum dynamic error of the filtered signal is equal to $1.33 \%$. The designed optimal value of the filter time constant is recommended to be applied for the analog input signal filtering in the automated system for the thermal plant control.

Application of the developed technique for designing the optimal value of the filter time constant in the automated measurement and control systems will ensure high quality of the filtration process and small dynamic error of the filtered signal.

\title{
References
}

[1] Hamming, R. W. Digital filters. 3rd ed. New Jersey: Prentice-Hall, Englewood-Cliffs, 1989, 284 p.

[2] H. Dimopoulos. Optimal use of some classical approximations in filter design. IEEE Transactions on Circuits and Systems II: Express Briefs, 2007, Vol. 54, Iss. 9, pp. 780 - 784. https://doi.org/10.1109/TCSII.2007.900345

[3] J. C. Ma, L. Luo, Q. B. Wu. A filter design method based on combination wavelets. MSSP, 1997, Vol. 11, Iss. 5, pp. 767 - 772. https://doi.org/10.1006/mssp.1997.0105

[4] Richard J. Lyons. Understanding digital signal processing. Third ed. Prentice Hall Publ. 1996, 992 p.

[5] N. K. Sinha, G. P. Rao. Identification of continuous-time systems: methodology and computer implementation. Kluwer Academic Publishers Norwell, 1991, 637 p. https://doi.org/10.1007/978-94-011-3558-0

[6] Adamenko V. O. Automation of the technical information processing: lectures course. Kyiv: I. Sikorsky KPI, 2017, 44 p. (in Ukrainian)

[7] Gren Y. V. Real-time systems programming: textbook. Lviv Polytechnic Publ. House, 2011, 324 p. (in Ukrainian)

[8] R. Fedoryshyn, S. Klos, V. Savytskyi, O. Masniak. Identification of controlled plant and development of its model by means of PLC. Energy Eng. Control Syst., 2016, Vol. 2, No. 2, pp. 69 - 78. https://doi.org/10.23939/jeecs2016.02.069

\section{Розрахунок оптимального фільтра аналогового сигналу}

\author{
Роман Федоришин ${ }^{a}$, Святослав Кльось $^{a}$, Володимир Савицький ${ }^{a}$, \\ Євген Пістун ${ }^{a}$, Мирослав Волошин ${ }^{b}$ \\ ${ }^{a}$ Національний університет «Львівська політехніка», вул. С. Бандери, 12, м. Львів, 79013, Україна \\ ${ }^{b}$ Гданська політехніка, вул. Г. Нарутовіча, 11/12, м. Гданськ, 80-233, Польща
}

\begin{abstract}
Анотація
Представлено методику розрахунку оптимального значення сталої часу фільтра аналогового сигналу на основі розробленого критерію оптимальності. Запропонований критерій враховує показник якості процесу фільтрування та динамічну похибку профільтрованого сигналу. Виконано експериментальне дослідження перехідних процесів у тепловому об'єкті з метою аналізу впливу параметрів фільтра на якість процесу фільтрування аналогового сигналу. Для отриманих експериментальних даних було розраховано оптимальне значення сталої часу фільтра на основі розробленої методики, що складається з восьми кроків. Здійснено порівняння експериментального перехідного процесу із профільтрованим процесом за допомогою фільтра 3 оптимальним значенням сталої часу. Застосування розробленої методики в автоматизованих системах вимірювання та керування забезпечить високу якість процесу фільтрування при незначній динамічній похибці профільтрованого сигналу.
\end{abstract}

Ключові слова: фільтр; стала часу; оптимізація; аналоговий сигнал; динамічна похибка; критерій оптимальності. 